\title{
Trial Design Model
}

National Cancer Institute

\section{Source}

National Cancer Institute. Trial Design Model. NCI Thesaurus. Code C142736.

A standard structure for representing the planned sequence of events and the treatment plan of a clinical trial. (CDISC) 